\title{
Elicitação com quitosana no crescimento e nos compostos voláteis de Mentha arvensis in vitro
}

\author{
Chitosan elicitation on growth and volatile compounds of Mentha arvensis in vitro
}

\author{
T. de Oliveira ${ }^{1}$; A. A. de Carvalho' ; S. K. V. Bertolucci' ${ }^{2}$ J. P. M. Rocha ${ }^{1}$; M. C. \\ Cossa $^{1}$; J. E. B. P. Pinto ${ }^{1 *}$ \\ ${ }^{I}$ Departamento de Agricultura/Laboratório de Cultura de Tecidos Vegetais/Setor de Plantas Medicinais, Universidade \\ Federal de Lavras, 37200-000, Lavras-Minas Gerais, Brasil \\ ${ }^{2}$ Departamento de Agricultura/Laboratório de Fitoquímica e Plantas Medicinais/Setor de Plantas Medicinais, \\ Universidade Federal de Lavras, 37200-000, Lavras-Minas Gerais, Brasil \\ *jeduardo@ufla.br
}

(Recebido em 09 de setembro de 2019; aceito em 17 de abril de 2020)

\begin{abstract}
Elicitores são substâncias com a capacidade de induzir a produção de metabólitos secundários específicos. Objetivou-se avaliar o efeito de quitosana suplementada no meio de cultura no crescimento, produção de pigmentos fotossintéticos e compostos voláteis de Mentha arvensis. Segmentos nodais de M. arvensis foram inoculados em meio MS suplementados com cinco concentrações de quitosana $\left(0,50,100,150\right.$ e $200 \mathrm{mg} \mathrm{L}^{-}$ ${ }^{1}$ ). Após 30 dias de cultivo, avaliou-se o comprimento de brotos, as biomassas secas de folha, caule, raiz e total. Além disso, as análises dos compostos voláteis e pigmentos fotossintéticos foram investigados. A adição de quitosana em $100 \mathrm{mg} \mathrm{L}^{-1}$ promoveu maiores acúmulos de biomassas secas em todos os órgãos avaliados. Por outro lado, maiores concentrações de quitosana (150 e $\left.200 \mathrm{mg} \mathrm{L}^{-1}\right)$ apresentaram efeito fitotóxico nas plântulas. Maiores teores de clorofila $a$ e carotenoides foram observados sem a suplementação com quitosana e clorofila $b$ com $200 \mathrm{mg} \mathrm{L}^{-1}$. A quitosana influenciou a concentração dos constituintes voláteis in vitro. Na menor concentração de quitosana $\left(50 \mathrm{mg} \mathrm{L}^{-1}\right)$ houve maior acúmulo de pulegona, $100 \mathrm{mg} \mathrm{L}^{-1}$ de limoneno e $200 \mathrm{mg} \mathrm{L}^{-1}$ de mentol e mentona.
\end{abstract}

Palavras-chave: hortelã, metabólitos secundários, micropropagação.

Elicitors are substances with the ability to induce the production of specific secondary metabolites. The objective of this study was to evaluate the effect of chitosan on growth, photosynthetic pigment production and volatile compounds of Mentha arvensis on culture medium. Nodal segments of M. arvensis were inoculated in MS medium supplemented with five chitosan concentrations $\left(0,50,100,150\right.$ and $\left.200 \mathrm{mg} \mathrm{L}^{-1}\right)$. After 30 days of cultivation, shoot length, leaf, shoot, root and total biomass were evaluated. In addition, analyzes of volatile compounds and photosynthetic pigments were investigated. The addition of chitosan in $100 \mathrm{mg} \mathrm{L}^{-1}$ promoted greater accumulation of dry biomass in all evaluated organs. On the other hand, high concentrations (150 e $200 \mathrm{mg} \mathrm{L}^{-1}$ ) showed phytotoxic effect on plantlets. Higher levels of chlorophyll $a$ and carotenoids were observed without chitosan and chlorophyll $b$ supplementation with $200 \mathrm{mg} \mathrm{L}^{-1}$. Chitosan influenced the concentration of volatile constituents in vitro. At the lowest concentration of chitosan $(50 \mathrm{mg}$ $\mathrm{L}^{-1}$ ) there was greater accumulation of pulegone, $100 \mathrm{mg} \mathrm{L}^{-1}$ limonene and $200 \mathrm{mg} \mathrm{L}^{-1}$ menthol and mentone. Keywords: mint, secondary metabolites, micropropagation.

\section{INTRODUÇÃO}

O gênero Mentha é um dos mais utilizados, que conta com 61 espécies, de acordo com a última classificação taxonômica, e está entre os principais pertencentes à família das Lamiaceae. São popularmente conhecidas como hortelã, muito utilizadas na medicina popular por possuir ação carminativa, hipotensora e antiespamódica, e combater distúrbios biliares, cólicas menstruais, dor de estômago, constipação [1, 2]. Atualmente, há um grande interesse pelo gênero, devido a importância comercial de seu óleo essencial, que é o mais comercializado do mundo, rico em monoterpenos. Dentre suas aplicações temos saborizantes de alimentos, perfumaria, confeitaria, fabricação de pasta de dente, além de utilizações na indústria farmacêutica [3].

Por meio da cultura de tecidos vegetais e o uso de elicitores bióticos e abióticos é possível estudar a produção de metabólitos secundários e o crescimento celular in vitro [4]. Elicitores são substâncias com a capacidade de induzir a produção de metabólitos secundários específicos. A indução ocorre quando moléculas sinalizadoras dos agentes patogênicos ou dos eliciadores ligam- 
se às moléculas receptoras na planta, desencadeando, a partir daí, diferentes respostas. Elicitores podem ser de origem biótica, como vírus, bactérias, fungos e nematóides, ou então produtos químicos dos mais variados grupos, que constituem os de origem abiótica [5]. Dentre esses produtos químicos, tem-se a quitosana, sendo elemento estrutural principal do exoesqueleto de insetos e crustáceos, e encontrado nas paredes celulares de uma variedade de fungos [6].

Alguns trabalhos reportam o efeito da quitosana na síntese de metabolitos secundários em plantas medicinais. A quitosana induziu o aumento das concentrações de compostos terpênicos como mentol, mentona e pulegona em cultura de células de Mentha piperita [7], limoneno em Citrus japônica [8], triterpenoides em Betula platyphylla [9] e artemisinina em Artemisia annua [10]. O uso de quitosana na cultura de células de Linum usitatissimum aumentou a produção de polifenóis [11]. A quitosana apresentou potencial para aumentar o acúmulo de biomassa e polifenóis em culturas de calos de Fagonia indica [12]. Malayaman et al. (2017) [13] relataram o uso de quitosana para aumentar a produção de tanino hidrolisável usando a cultura de suspensão celular em $P$. debilis.

Nesse sentido, objetivou-se avaliar o efeito da elicitação com quitosana adicionadas ao meio de cultura no crescimento, na produção de pigmentos fotossintéticos e compostos voláteis de Mentha arvensis in vitro.

\section{MATERIAL E MÉTODOS}

\subsection{Fase de estabelecimento}

Segmentos nodais $(1 \mathrm{~cm})$ de Mentha arvensis foram utilizados como explantes para $\mathrm{o}$ estabelecimento e lavados em água corrente por 30 minutos. Em seguida, foram imersos em solução de hipoclorito de sódio comercial a 50\% e mantidos sob agitação constante, por 15 minutos, seguido de cinco lavagens em água destilada autoclavada. Os explantes foram inoculados em tubos de ensaio contendo a metade da força do MS [14] - (1/2MS) suplementado com $15 \mathrm{~g} \mathrm{~L}^{-1}$ de sacarose, $\mathrm{pH}(5,7 \pm 0,1)$, fotoperíodo de $16 \mathrm{~h}$ luz/8 h escuro, intensidade luminosa de $39 \mu \mathrm{mol} \mathrm{m} \mathrm{m}^{-2} \mathrm{~s}^{-1} \mathrm{e}$ temperatura de $26 \pm 1^{\circ} \mathrm{C}$. As plântulas estabelecidas com idade de 30 dias foram multiplicadas no mesmo meio de estabelecimento e mantidas nas mesmas condições de cultivo para formação de um estoque de plântulas que foram usadas nos experimentos.

\subsection{Condições gerais dos experimentos}

O meio de cultura utilizado foi o mesmo da fase de estabelecimento ( $1 / 2 \mathrm{MS})$ solidificado com 6 $\mathrm{g} \mathrm{L}^{-1}$ de ágar e mantidos nas mesmas condições da sala de crescimento. Aos 30 dias foram avaliados o comprimento das brotações, biomassa seca da folha, caule, raiz total, assim como a composição da fração volátil, e a quantificação de pigmentos fotossintéticos. Para a determinação das biomassas secas, cada parte da plântula foram colocadas em sacos de papel kraft e acondicionadas em estufa de circulação forçada de ar, a $37^{\circ} \mathrm{C}$, até peso constante.

\subsection{Efeito da quitosana no crescimento in vitro de Mentha arvensis}

Segmentos nodais de aproximadamente $1 \mathrm{~cm}$ de comprimento, advindos de plântulas estabelecidas em $1 / 2 \mathrm{MS}$, foram inoculados verticalmente em tubos de ensaio, contendo $15 \mathrm{~mL}$ do mesmo meio e em cinco diferentes concentrações de quitosana $\left(0 ; 50 ; 100 ; 150 ; 200 \mathrm{mg} \mathrm{L}^{-1}\right)$. A quitosana (pó) de baixo peso molecular (50-190 KDa) da Sigma-Aldrich ${ }^{\circledR}$ Chemicals, SP, Brasil foi utilizada. Para isto, uma solução estoque na concentração de $4000 \mathrm{mg} \mathrm{L}^{-1}$ foi preparada com a diluição da quitosana em uma solução ácida com $1 \%$ de ácido acético, sob agitação constante. Em seguida, as concentrações finais relativas ao volume de meio de cultura foram adicionadas e o $\mathrm{pH}$ foi corrigido para $5,7 \pm 0,1$. Posteriormente, a autoclavagem do meio de cultura foi realizada a $120^{\circ} \mathrm{C}$ e $1 \mathrm{~atm}$, por 20 minutos. Utilizou-se o delineamento experimental inteiramente casualizado (DIC), com 5 tratamentos, 5 repetições com 4 tubos por repetição e 1 explante por tubo. 


\subsection{Quantificação dos pigmentos fotossintéticos}

A extração e quantificação das clorofilas $a$ e $b$, e carotenóides, foram realizadas segundo a metodologia de Lichtenthaler e Buschmann (2001) [15]. Amostras de 0,2g da matéria fresca das folhas foram homogeneizadas em $40 \mathrm{~mL}$ de acetona $80 \%$, seguida da leitura em espectrofotômetro nos comprimentos de onda 663, 645 e $470 \mathrm{~nm}$, respectivamente. Os procedimentos foram realizados na ausência de luz para evitar a degradação dos pigmentos. Os valores foram obtidos em miligrama de pigmento por grama de matéria fresca.

\subsection{Análise química da fração volátil}

As análises químicas da fração volátil foram realizadas em um sistema de cromatografia em fase gasosa Agilent ${ }^{\circledR}$ 7890A acoplado a um detector seletivo de massas Agilent ${ }^{\circledR}$ MSD 5975C (Agilent Tchnologies, Califórnia, EUA), operado por ionização de impacto eletrônico a $70 \mathrm{eV}$, em modo varredura, a uma velocidade de $1,0 \mathrm{scan} / \mathrm{s}$, com intervalo de aquisição de massas de 40-400 m/z.

Para extração da fração volátil empregou-se a técnica de headspace estático. Para isso, utilizouse do extrator/amostrador headspace automático CombiPAL Autosampler System (CTC Analytics $A G$, Switzerland) acoplado ao sistema de CG/EM. Após procedimentos de otimização das condições operacionais, estabeleceram-se $30 \mathrm{~min}$ de incubação das amostras a $110^{\circ} \mathrm{C}$ e a temperatura da seringa foi programada para $120^{\circ} \mathrm{C}$. Folhas foram coletadas de plântulas cultivadas in vitro e secas em estufa de circulação de ar a $37^{\circ} \mathrm{C}$. Alíquotas de $20 \mathrm{mg}$ de folhas secas, em triplicatas, que foram acondicionadas em vial para headspace de $20 \mathrm{~mL}$, vedados com septo de silicone/PTFE até a análise; $500 \mu \mathrm{L}$ da fase de vapor foram injetados na coluna cromatográfica.

Utilizou-se uma coluna capilar de sílica fundida DB-WAX (30 m de comprimento x 0,25 mm de diâmetro interno x 0,25 $\mu \mathrm{m}$ de espessura do filme) (Califórnia, EUA). Hélio foi utilizado como gás de arraste com fluxo de $1,0 \mathrm{~mL} \min ^{-1}$. A injeção foi realizada no modo split a uma razão de injeção de 1:50. As temperaturras do injetor e da linha de transferência para o EM, foram mantidas em $230^{\circ} \mathrm{C}$, seguido por uma rampa de temperatura de $3^{\circ} \mathrm{C} \min ^{-1}$ até $100^{\circ} \mathrm{C}$, seguida de uma rampa de $15^{\circ} \mathrm{C} \mathrm{min}{ }^{-1}$ até $220^{\circ} \mathrm{C}$. Os componentes foram identificados por comparação de seus tempos de retenção relativos e por comparação dos espectros de massas do banco de dados da biblioteca NIST/NHI (2008) [16] e de acordo com Adams (2007) [17].

\subsection{Análises estatísticas}

Os dados obtidos foram submetidos à ANOVA pelo teste $\mathrm{F}(\mathrm{p}<0,05)$ e as médias dos tratamentos foram comparadas pelo teste de Scott-Knott $(\mathrm{p}<0,05)$, utilizando-se o software Sisvar ${ }^{\circledR}$, versão 5.0 [18]. O software Statistica ${ }^{\circledR}$, version 13.4 (StatSoft - Tulsa, USA) foi utilizado para a análise de componentes principais (PCA).

\section{RESULTADOS E DISCUSSÃO}

\subsection{Efeito da quitosana no crescimento in vitro de Mentha arvensis}

As diferentes concentrações de quitosana influenciaram o crescimento de Mentha arvensis. Todos os parâmetros avaliados apresentaram diferenças significativas entre os tratamentos (Tabela 1). A presença do elicitor na concentração de $100 \mathrm{mg} \mathrm{L}^{-1}$ proporcionou maior comprimento de broto $(5,96 \mathrm{~cm})$ e maiores biomassas secas de folha $(54,43 \mathrm{mg})$, caule $(20,83 \mathrm{mg})$, raiz $(18,37 \mathrm{mg})$ e total $(93,63 \mathrm{mg})$ em comparação aos demais tratamentos. Observa-se ainda que as concentrações acima de $100 \mathrm{mg} \mathrm{L}^{-1}$ reduziram o crescimento das plântulas, afetando o comprimento de broto e as biomassas secas de M. arvensis. Portanto, concentrações apropriadas de quitosana adicionadas ao meio de cultura podem estimular o crescimento de M. arvensis. 
Tabela 1 - Efeito de diferentes concentrações de quitosana no comprimento do broto (CB), biomassa seca do caule (BSC), folha (BSF), raiz (BSR) e total (BST) de Mentha arvensis in vitro.

\begin{tabular}{cccccc}
\hline $\begin{array}{c}\text { Quitosana } \\
\left(\mathbf{m g ~ L}^{-1}\right)\end{array}$ & $\begin{array}{c}\mathbf{C B} \\
(\mathbf{c m})\end{array}$ & $\begin{array}{c}\text { BSF } \\
(\mathbf{m g})\end{array}$ & $\begin{array}{l}\text { BSC } \\
(\mathbf{m g})\end{array}$ & $\begin{array}{c}\text { BSR } \\
(\mathbf{m g})\end{array}$ & $\begin{array}{c}\text { BST } \\
(\mathbf{m g})\end{array}$ \\
\hline $\mathbf{0}$ & $4,08 \pm 0,59 \mathrm{~b}$ & $31,45 \pm 4,94 \mathrm{~b}$ & $11,28 \pm 1,35 \mathrm{~b}$ & $11,40 \pm 0,41 \mathrm{c}$ & $54,13 \pm 6,34 \mathrm{~b}$ \\
$\mathbf{5 0}$ & $4,63 \pm 0,84 \mathrm{~b}$ & $33,23 \pm 4,54 \mathrm{~b}$ & $13,87 \pm 1,93 \mathrm{~b}$ & $13,48 \pm 1,49 \mathrm{~b}$ & $60,57 \pm 6,96 \mathrm{~b}$ \\
$\mathbf{1 0 0}$ & $5,96 \pm 0,89 \mathrm{a}$ & $54,43 \pm 3,88 \mathrm{a}$ & $20,83 \pm 1,37 \mathrm{a}$ & $18,37 \pm 1,39 \mathrm{a}$ & $93,63 \pm 6,38 \mathrm{a}$ \\
$\mathbf{1 5 0}$ & $2,21 \pm 0,31 \mathrm{c}$ & $26,98 \pm 5,24 \mathrm{~b}$ & $8,53 \pm 2,35 \mathrm{c}$ & $6,48 \pm 1,70 \mathrm{~d}$ & $41,98 \pm 8,90 \mathrm{c}$ \\
$\mathbf{2 0 0}$ & $2,26 \pm 0,40 \mathrm{c}$ & $35,85 \pm 6,55 \mathrm{~b}$ & $11,23 \pm 2,00 \mathrm{~b}$ & $8,05 \pm 1,42 \mathrm{~d}$ & $55,13 \pm 9,94 \mathrm{~b}$ \\
\hline
\end{tabular}

* Médias ( \pm desvio padrão) seguidas das mesmas letras na coluna não diferem entre si pelo Teste de Scott Knott $(p<0,05)$.

Por meio da Figura 1, pode-se observar que a presença do elicitor influenciou o crescimento de plântulas de M. arvensis. Um aumento de $46 \%$ no comprimento de brotos foi observado com adição de $100 \mathrm{mg} \mathrm{L}^{-1}$ de quitosana comparado com o controle (Tabela 1). Em relação ao acúmulo de biomassa seca, a suplementação de $100 \mathrm{mg} \mathrm{L}^{-1}$ de quitosana no meio de cultura induziu maior acúmulo de folha $(73 \%)$, caule $(84 \%)$ e raiz $(61 \%)$, totalizando assim, um ganho de $73 \%$ na biomassa seca total em relação ao controle. A quitosana funcionou, possivelmente, como fonte de nitrogênio orgânico para induzir o maior comprimento de broto e biomassas de $M$. arvensis. A quitosana é um polímero policatiônico $\beta-1,4$ ligado à $\mathrm{D}$-glucosamina definido como um diacetilato de quitina extraído de crustáceos [19]. Ohta et al. (1999) [20] sugerem que esse ganho no crescimento é atribuído ao teor de $8,7 \%$ de nitrogênio contido na quitosana. Outros autores relatam que a quitosana incrementa o crescimento de plântulas devido estar relacionada à biossíntese de auxinas por uma via independente do triptofano. Além disso, a quitosana pode induzir um sinal para sintetizar hormônios de crescimento, como as giberelinas [21]. Entretanto, doses mais elevadas (150 e $200 \mathrm{mg} \mathrm{L}^{-1}$ ) inibiram o crescimento de M. arvensis, demonstrando assim efeito fitotóxico.

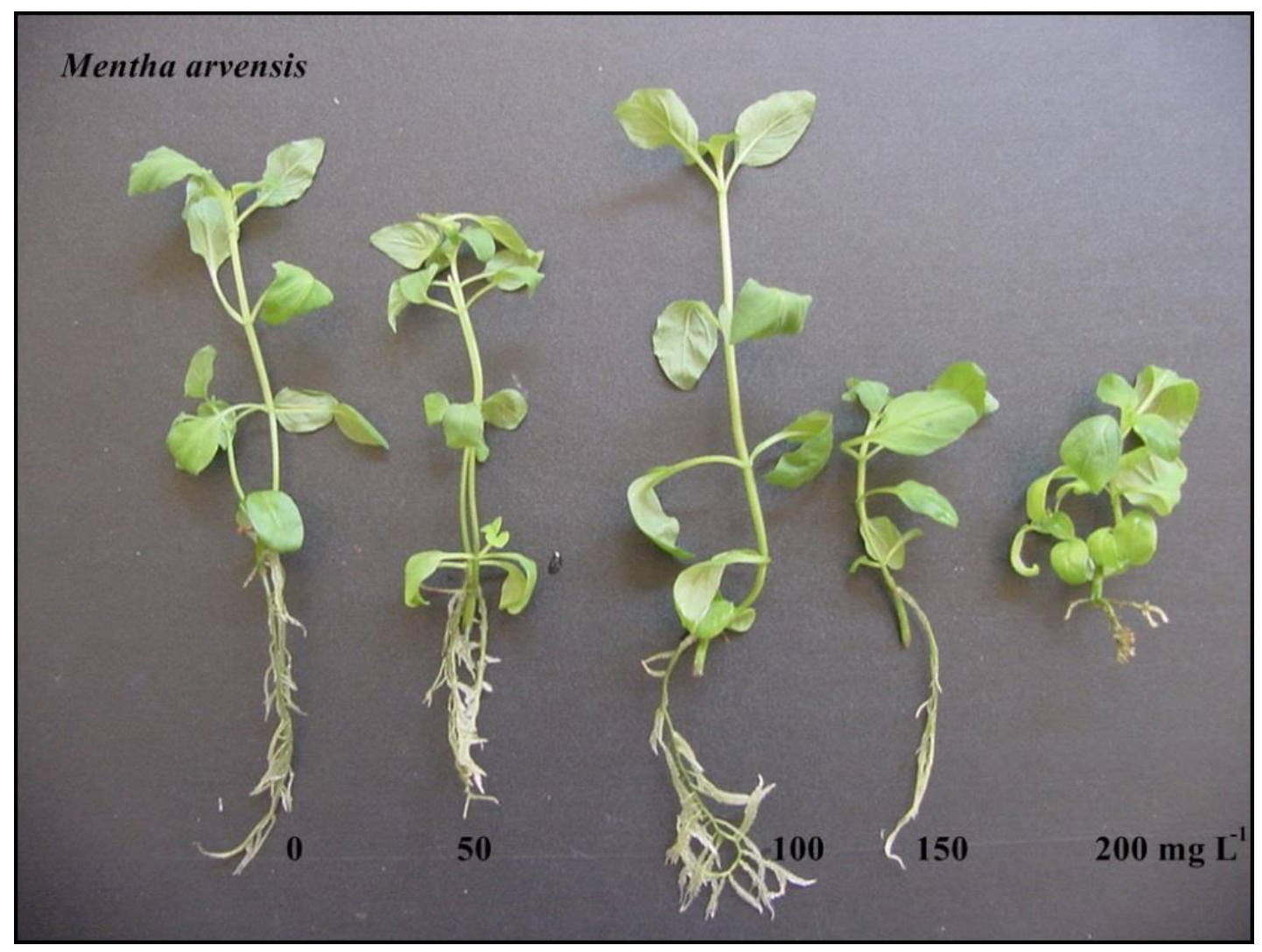

Figura 1- Mentha arvensis sob diferentes concentrações de quitosana $\left(0,50,100,150\right.$ e $\left.200 \mathrm{mg} \mathrm{L}^{-1}\right)$ após 30 dias de cultivo in vitro. 
O potencial da quitosana em aumentar o comprimento de brotos e acúmulo de biomassa de plântulas cultivadas in vitro já foi demonstrado por outros autores. A adição de $10 \mathrm{mg} \mathrm{L}^{-1} \mathrm{de}$ quitosana no meio de cultura aumentou notavelmente o acúmulo da biomassa e potencial antioxidante das células de Linum usitatissimum L. [11]. A cultura de calos de F. indica apresentaram melhor produção de biomassa com suplementação de quitosana [12]. Ait Barka et al. (2004) [22] reportaram que a adição de $1,75 \%\left(\mathrm{v} \mathrm{v}^{-1}\right)$ de chitogel, produto à base de quitosana, em meio de cultura promoveu aumento no comprimento dos brotos e peso seco de raízes e brotos de Vitis vinifera cv. Chardonnay in vitro. No entanto, esses autores relatam ainda que a concentração de $2 \%$ de chitogel teve efeito negativo no crescimento das plântulas e concentrações maiores promoveram morte das mesmas. De acordo com Maia et al. (2010) [23], a quitosana apresentou efeito fitotóxico em plântulas de videira cv. Merlot, reduzindo a porcentagem de brotação e enraizamento, o comprimento médio da parte aérea e a massa fresca da planta toda.

\subsection{Efeito da quitosana nos pigmentos fotossintéticos e carotenoides}

A presença da quitosana no meio de cultura in vitro influenciou os teores de pigmentos fotossintéticos e carotenoides (Tabela 2). No geral, os teores de clorofila $a$ e carotenoides foram inibidos pelo elicitor. Os maiores teores de clorofila $a\left(1,50 \mathrm{mg} \mathrm{g}^{-1} \mathrm{MF}\right)$, total $\left(2,96 \mathrm{mg} \mathrm{g}^{-1} \mathrm{MF}\right) \mathrm{e}$ carotenoides $\left(1,02 \mathrm{mg} \mathrm{g}^{-1} \mathrm{MF}\right)$ foram observados sem a adição de quitosana no meio de cultura. Por outro lado, a maior concentração de quitosana $\left(200 \mathrm{mg} \mathrm{L}^{-1}\right)$ proporcionou o mais alto teor de clorofila $b\left(1,93 \mathrm{mg} \mathrm{g}^{-1} \mathrm{MF}\right)$.

Tabela 2- Efeito de diferentes concentrações de quitosana no teor de pigmentos de Mentha arvensis aos 30 dias in vitro.

\begin{tabular}{|c|c|c|c|c|}
\hline \multirow{2}{*}{$\begin{array}{r}\text { Quitosana } \\
\left(\mathrm{mg} \mathrm{L}^{-1}\right)\end{array}$} & \multicolumn{3}{|c|}{ Clorofila (mg g-1 MF) } & \multirow{2}{*}{ Carotenóides $\left(\mathrm{mg} \mathrm{g}^{-1} \mathrm{MF}\right)$} \\
\hline & $a$ & $b$ & Total & \\
\hline $\mathbf{0}$ & $1,50 \pm 0,00 \mathrm{a}$ & $1,46 \pm 0,08 b$ & $2,96 \pm 0,08 a$ & $1,02 \pm 0,14 a$ \\
\hline 50 & $0,48 \pm 0,11 b$ & $1,61 \pm 0,14 b$ & $2,09 \pm 0,19 b$ & $0,53 \pm 0,04 b$ \\
\hline 100 & $0,24 \pm 0,06 c$ & $1,26 \pm 0,17 b$ & $1,49 \pm 0,18 \mathrm{c}$ & $0,53 \pm 0,06 b$ \\
\hline 150 & $0,30 \pm 0,03 c$ & $1,42 \pm 0,04 \mathrm{~b}$ & $1,72 \pm 0,04 \mathrm{c}$ & $0,47 \pm 0,11 b$ \\
\hline 200 & $0,29 \pm 0,02 \mathrm{c}$ & $1,93 \pm 0,14 \mathrm{a}$ & $2,23 \pm 0,16 \mathrm{~b}$ & $0,55 \pm 0,08 \mathrm{~b}$ \\
\hline
\end{tabular}

* Médias ( \pm desvio padrão) seguidas das mesmas letras na coluna não diferem entre si pelo Teste de Scott Knott $(p<0,05)$.

A clorofila $b$ é sintetizada através da oxidação do grupo metil da clorofila $a$ para um grupo aldeído. Sabe-se que a clorofila $b$ é convertida em clorofila $a$ através de uma enzima chamada clorofila $a$ oxigenase, que catalisa a conversão do grupo metil ao grupo aldeído [24]. Desta forma, a quitosana em maior concentração $\left(200 \mathrm{mg} \mathrm{L}^{-1}\right)$ pode ter agido no sentido de estimular a produção de clorofila $b$ e inibiu a produção dos demais pigmentos, e por isso, quando a clorofila $b$ apresenta em maior teor (1,93 $\left.\mathrm{mg} \mathrm{g}^{-1} \mathrm{MF}\right)$ ocorre redução no teor de clorofila $a\left(0,29 \mathrm{mg} \mathrm{g}^{-1} \mathrm{MF}\right)$.

\subsection{Efeito da quitosana nos compostos voláteis}

Os resultados das análises cromatográficas indicam influências quantitativas quando o meio de cultura foi suplementado com quitosana no cultivo in vitro de $M$. arvensis (Tabela 3). Um total de 17 constituintes foi identificado totalizando acima de $98 \%$ da composição química total da fração volátil em $M$. arvensis, apenas a concentração de $200 \mathrm{mg} \mathrm{L}^{-1}$ resultou em 16 constituintes. Quatro constituintes majoritários foram identificados, sendo limoneno, mentona, pulegona e mentol, totalizando acima de $87 \%$ da composição química. 
Tabela 3 - Teor (\% \pm desvio padrão) de constituintes voláteis de plântulas de Mentha arvensis oriundas de segmentos nodais cultivadas in vitro, aos 30 dias, sob diferentes doses de quitosana.

\begin{tabular}{|c|c|c|c|c|c|c|}
\hline Constituintes & TR & $0 \mathrm{mg}$ & $50 \mathrm{mg}$ & $100 \mathrm{mg}$ & $150 \mathrm{mg}$ & $200 \mathrm{mg}$ \\
\hline$\alpha$-pineno & 2,33 & $1,60 \pm 0,12$ & $1,56 \pm 0,13$ & $1,54 \pm 0,03$ & $1,36 \pm 0,02$ & $1,42 \pm 0,03$ \\
\hline$\beta$-pineno & 3,32 & $1,35 \pm 0,09$ & $1,35 \pm 0,13$ & $1,33 \pm 0,03$ & $1,16 \pm 0,02$ & $1,19 \pm 0,02$ \\
\hline Sabineno & 3,51 & $0,77 \pm 0,06$ & $0,74 \pm 0,08$ & $0,75 \pm 0,01$ & $0,64 \pm 0,03$ & $0,72 \pm 0,03$ \\
\hline Mirceno & 4,22 & $0,91 \pm 0,17$ & $0,89 \pm 0,14$ & $0,94 \pm 0,07$ & $0,79 \pm 0,04$ & $0,99 \pm 0,02$ \\
\hline limoneno & 4,94 & $3,06 \pm 0,97$ & $2,48 \pm 0,85$ & $4,85 \pm 1,69$ & $2,58 \pm 0,11$ & $3,68 \pm 0,47$ \\
\hline 3-octanol & 10,82 & $0,69 \pm 0,03$ & $0,75 \pm 0,09$ & $0,64 \pm 0,04$ & $0,57 \pm 0,03$ & $0,59 \pm 0,08$ \\
\hline Mentona & 12,70 & $6,54 \pm 2,19$ & $3,34 \pm 0,63$ & $5,36 \pm 1,87$ & $4,42 \pm 0,25$ & $7,05 \pm 0,35$ \\
\hline Iso-mentona & 13,67 & $1,57 \pm 0,26$ & $1,08 \pm 0,12$ & $1,34 \pm 0,42$ & $1,81 \pm 0,11$ & $2,59 \pm 0,03$ \\
\hline Linalol & 16,16 & $1,04 \pm 0,11$ & $0,95 \pm 0,10$ & $1,08 \pm 0,07$ & $1,05 \pm 0,07$ & $1,21 \pm 0,02$ \\
\hline Iso-pulegona & 16,34 & $0,34 \pm 0,05$ & $0,40 \pm 0,03$ & $0,42 \pm 0,10$ & $0,21 \pm 0,03$ & $\mathrm{Nd}$ \\
\hline Iso-pulegol & 16,50 & $0,85 \pm 0,33$ & $1,12 \pm 0,04$ & $0,87 \pm 0,13$ & $0,80 \pm 0,04$ & $0,54 \pm 0,03$ \\
\hline$\beta$-cariofileno & 16,84 & $0,31 \pm 0,04$ & $0,33 \pm 0,02$ & $0,31 \pm 0,03$ & $0,30 \pm 0,03$ & $0,34 \pm 0,03$ \\
\hline Iso-mentol & 17,14 & $0,93 \pm 0,37$ & $0,65 \pm 0,10$ & $0,75 \pm 0,26$ & $1,22 \pm 0,04$ & $1,54 \pm 0,04$ \\
\hline Iso-pulegol & 17,20 & $0,15 \pm 0,11$ & $0,17 \pm 0,03$ & $0,14 \pm 0,04$ & $0,14 \pm 0,02$ & $0,09 \pm 0,02$ \\
\hline Pulegona & 17,83 & $\begin{array}{c}40,33 \pm 8,4 \\
5\end{array}$ & $54,06 \pm 1,57$ & $\begin{array}{c}46,00 \pm 10,4 \\
5\end{array}$ & $\begin{array}{c}31,58 \pm 1,7 \\
0\end{array}$ & $14,63 \pm 0,99$ \\
\hline Mentol & 17,93 & $\begin{array}{c}38,14 \pm 7,1 \\
6\end{array}$ & $28,48 \pm 3,32$ & $32,20 \pm 9,49$ & $\begin{array}{c}49,94 \pm 1,6 \\
2\end{array}$ & $61,64 \pm 0,82$ \\
\hline $\begin{array}{c}\text { Germacreno } \\
\text { D }\end{array}$ & 18,70 & $0,40 \pm 0,03$ & $0,39 \pm 0,04$ & $0,41 \pm 0,01$ & $0,36 \pm 0,02$ & $0,40 \pm 0,01$ \\
\hline Total (\%) & - & 98,98 & 98,77 & 98,92 & 98,91 & 98,62 \\
\hline $\begin{array}{l}\text { Número de } \\
\text { constituintes }\end{array}$ & - & 17 & 17 & 17 & 17 & 16 \\
\hline
\end{tabular}

TR: Tempo de retenção; $N d$ : Não detectado.

A análise de componentes principais (PCA) foi utilizada para estudar o efeito das concentrações de quitosana adicionadas ao meio de cultivo na produção dos principais compostos majoritários de M. arvensis (Figura 2). Observa-se que o teor de mentol e mentona aumentaram com a maior concentração de quitosana $\left(200 \mathrm{mg} \mathrm{L}^{-1}\right)$. Na concentração de $50 \mathrm{mg} \mathrm{L}^{-1}$ ocorreu aumento de pulegona. Na análise de loadings, observa-se ainda correlação inversa dos vetores que representam a pulegona e o mentol. Portanto, à medida que se aumenta o teor de pulegona ocorre a diminuição do mentol. Isto é devido à pulegona ser um precursor do mentol. Com a menor dose há um acúmulo de pulegona que não converte para o mentol. Com o aumento há um fluxo para a síntese de mentol.
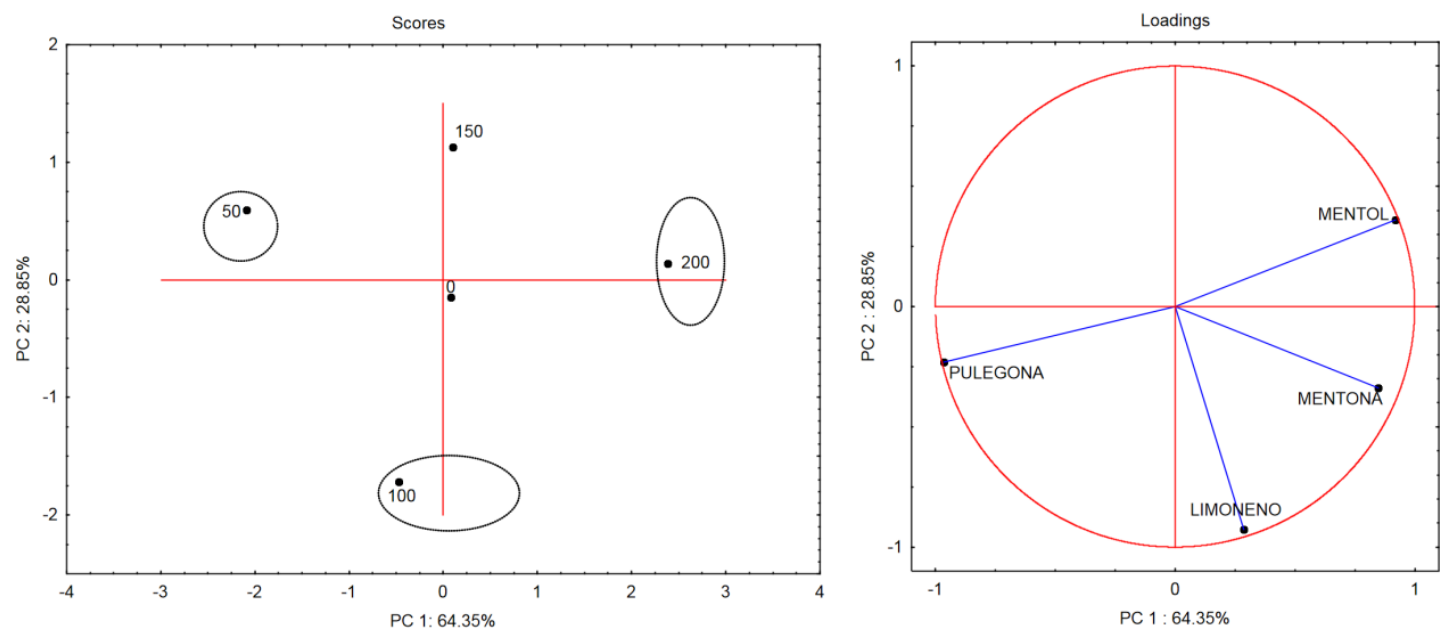

Figura 2- Análises de componentes principais dos compostos majoritários de M. arvensis cultivados aos 30 dias in vitro sob diferentes concentrações de quitosana (0, 50, 100, 150 e $\left.200 \mathrm{mg} \mathrm{L}^{-1}\right)$. 
Na rota biossintética, a pulegona é convertida em mentona, e depois para mentol. Isto demonstra que com maiores concentrações de quitosana no meio de cultura, a pulegona é convertida para mentol e em taxas menores a conversão é menor. A pulegona é a precursora do mentol, que é um dos compostos considerados mais significativos dos óleos de Mentha spp. A pulegona pode reduzir a (-)-mentona e sintetizar mentol, através da pulegona redutase, ou oxidar a (+)-mentofurano, pela mentofurano sintase [25].

Observa-se ainda que a maior concentração de limoneno ocorreu com a adição de $100 \mathrm{mg} \mathrm{L}^{-1}$ de quitosana ao meio (Tabela 3 e Figura 2). O geranil difosfato origina o linalol, limoneno e hidrato de sabineno e o limoneno. O limoneno é precursor dos principais monoterpenos de Mentha, e é obtido a partir do pirofosfato de geranil por isomerização cis-trans da ligação dupla. É o precursor da carvona e pulegona, que por reações sucessivas pode formar mentofurano, mentona, isomentona, mentol e seus isômeros e acetato de mentila [26].

Elicitação é uma técnica em que elicitores alteram o conteúdo dos metabolitos secundários bioativos das plantas pela indução das vias enzimáticas [27]. Assim como ocorreu nesta pesquisa em que a quitosana influenciou os compostos voláteis de $M$. arvensis. Outros trabalhos in vitro também reportam a adição de quitosana no estimulo da produção de metabolitos secundários. A adição de quitosana estimulou a produção dos terpenos como mentol, mentona, pulegona, linalol, limoneno em Mentha piperita [7] e limoneno em Citrus japônica [8]. A cultura de calo de Fagonia indica suplementada com quitosana exibiu níveis mais altos de compostos fenólicos e flavonoides, e atividade antioxidantes [12]. A adição de $150 \mathrm{mg}$ de quitosana, em $100 \mathrm{~mL}$ de meio líquido MS, aumentou o nível de tanino hidrolisável em suspensão de células de Phyllanthus debilis na fase estacionária [13]. A produção de artemisinina de Artemisia annua em cultura de raízes aumentou seis vezes com a adição de quitosana [10]. Raízes de Hypericum perforatum, cultivadas in vitro com a adição da quitosana ao meio, os níveis de valina, isoleucina, glutamina, ácido $\gamma$ aminobutírico, frutose, sacarose, ácidos graxos poliinsaturados, epicatequina, xantonas, dimetilalil-pirofosfato e estigmasterol aumentaram, enquanto os níveis de histidina diminuíram [28]. Trabalhos de suspensão celular com Scrophularia striata Boiss também constaram que a quitosana induziu a produção de fenilpropanóides [29]. Sendo assim, a aplicação de quitosana como elicitor, pode ser considerada uma perspectiva promissora na produção de metabólitos secundários, como o mentol em $M$. arvensis, sem a necessidade de uma alteração genética na planta.

\section{CONCLUSÃO}

A quitosana influenciou o crescimento, a produção de pigmentos fotossintéticos e de constituintes voláteis de $M$. arvensis. A presença do elicitor na concentração de $100 \mathrm{mg} \mathrm{L}^{-1}$ induziu maior comprimento de plântulas e acúmulo de biomassas secas. Entretanto, doses mais elevadas (150 e $200 \mathrm{mg} \mathrm{L}^{-1}$ ) inibiram o crescimento, demonstrando assim efeito fitotóxico. Baixas concentrações $\left(50 \mathrm{mg} \mathrm{L}^{-1}\right)$ de quitosana induziu a síntese de pulegona, intermediaria $\left(100 \mathrm{mg} \mathrm{L}^{-1}\right)$ de limoneno e altas concentrações $\left(200 \mathrm{mg} \mathrm{L}^{-1}\right)$ de mentol e mentona.

\section{AGRADECIMENTOS}

À Coordenação de Aperfeiçoamento de Pessoal de Nível Superior (Capes - código de financiamento 001), ao Conselho Nacional de Desenvolvimento Científico e Tecnológico (CNPq) e Fundação de Pesquisa de Minas Gerais (FAPEMIG), pelo auxílio financeiro e concessão de bolsas de estudo e produtividade.

\section{REFERÊNCIAS BIBLIOGRÁFICAS}

1. Brahmi F, Hauchard D, Guendouze N, Madani K, Kiendrebeogo M, Kamagaju L, et al. Phenolic composition, in vitro antioxidant effects and tyrosinase inhibitory activity of three Algerian Mentha species: M. spicata (L.), M. pulegium (L.) and M. rotundifolia (L.) Huds (Lamiaceae). Ind Crops Prod. 2015;74:722-30, doi: 10.1016/j.indcrop.2015.04.038 
2. Brahmi F, Madani K, Caroline S, Mohamed C, Duez P. Algerian mint species: HPTLC quantitative determination of rosmarinic acid and in vitro inhibitory effects on linoleic acid peroxidation. J Coastal Life Med. 2014;2:986-92, doi: 10.12980/jclm.2.2014apjtb-2014-0027

3. Choudhury RP, Kumar A, Garg AN. Analysis of Indian mint (Mentha spicata) for essential, trace and toxic elements and its antioxidant behaviour. J Pharm Biomed Anal. 2006;41(3):825-32, doi: 10.1016/j.jpba.2006.01.048

4. Boonsnongcheep P, Korsangruang S, Soonthornchareonnon N, Chintapakorn Y, Saralamp P, Prathanturarug S. Growth and isoflavonoid accumulation of Pueraria candollei var. candollei and $P$. candollei var. mirifica cell suspension cultures. Plant Cell Tiss Org. 2010;101(2):119-26, doi: 10.1007/s11240-010-9668-x

5. Angelova Z, Georgiev S, Roos W. Elicitation of Plants. Biotechnol Biotechnol Equip. 2006;20(2):72-83, doi: $10.1080 / 13102818.2006 .10817345$

6. Bittelli M, Flury M, Campbell GS, Nichols EJ. Reduction of transpiration through foliar application of chitosan. Agric For Meteorol. 2001;107(3):167-75, doi: 10.1016/S0168-1923(00)00242-2

7. Chang JH, Shin JH, Chung IS, Lee HJ. Improved menthol production from chitosan-elicited suspension culture of Mentha piperita. Biotechnol Lett. 1998;20(12):1097-9, doi: 10.1023/A:1005396924568

8. Lockwood GB, Bunrathep S, Songsak T, Ruangrungsi N. Production of d-Limonene in chitosan elicited Citrus japonica suspension cultures. J Essent Oil Res. 2007;19(2):113-6, doi: $10.1080 / 10412905.2007 .9699242$

9. Fan G, Li X, Wang X, Zhai Q, Zhan Y. Chitosan activates defense responses and triterpenoid production in cell suspension cultures of Betula platyphylla Suk. Afr J Biotecnol 2010;9(19)

10. Putalun W, Luealon W, De-Eknamkul W, Tanaka H, Shoyama Y. Improvement of artemisinin production by chitosan in hairy root cultures of Artemisia аппиа L. Biotechnol Lett. 2007;29(7):1143-6, doi: 10.1007/s10529-007-9368-8

11. Ahmad W, Zahir A, Nadeem M, Garros L, Drouet S, Renouard S, et al. Enhanced production of lignans and neolignans in chitosan-treated flax (Linum usitatissimum L.) cell cultures. Process Biochem. 2019;79:155-65, doi: 10.1016/j.procbio.2018.12.025

12. Khan T, Khan T, Hano C, Abbasi BH. Effects of chitosan and salicylic acid on the production of pharmacologically attractive secondary metabolites in callus cultures of Fagonia indica. Ind Crop Prod. 2019;129:525-35, doi: 10.1016/j.indcrop.2018.12.048

13. Malayaman V, Sisubalan N, Senthilkumar RP, Mohamed SS, Ranjithkumar R, Basha MG. Chitosan mediated enhancement of hydrolysable tannin in Phyllanthus debilis Klein ex Willd via plant cell suspension culture. Int J Biol Macromol. 2017;104:1656-63, doi: 10.1016/j.ijbiomac.2017.03.138

14. Murashige T, Skoog F. A Revised Medium for Rapid Growth and Bio Assays with Tobacco Tissue Cultures. Physiol Plant. 1962;15(3):473-97, doi: 10.1111/j.1399-3054.1962.tb08052.x

15. Lichtenthaler HK, Buschmann C. Chlorophylls and Carotenoids: Measurement and Characterization by UV-VIS Spectroscopy. Current Protocols Food Anal Chem. 2001;1(1):F4.3.1-F4.3.8, doi: 10.1002/0471142913.faf0403s 01

16. NIST. PC version 2.0 of the NIST/EPA/NIH mass spectral library. Gaithersburg: National Institute of Standards and Technology; 2008.

17. Adams RP. Identification of essential oil components by gas chromatography/mass spectrometry. Illinois: Allured Publishing Corporation; 2007. 804 p.

18. Ferreira DF. Sisvar: a computer statistical analysis system. Ci Agrotecnol. 2011;35:1039-42.

19. Khor E. Chitin: Fulfilling a Biomaterials Promise: Second Edition. Biomaterials. 2001;23:3913-5.

20. Ohta K, Taniguchi A, Konishi N, Hosoki T. Chitosan Treatment Affects Plant Growth and Flower Quality in Eustoma grandiflorum. Hortscience. 1999;34(2):233-4, doi: 10.21273/hortsci.34.2.233

21. Uthairatanakij A, Teixeira da Silva J, Obsuwan K. Chitosan for Improving Orchid Production and Quality. Orchid Sci Biotechnol. 2007;1:1-5.

22. Ait Barka E, Eullaffroy P, Clément C, Vernet G. Chitosan improves development, and protects Vitis vinifera L. against Botrytis cinerea. Plant Cell Rep. 2004;22(8):608-14, doi: 10.1007/s00299-003-07333

23. Maia AJ, Leite CD, Botelho RV, Faria CMDR, Uber SC. Efeitos da quitosana no desenvolvimento in vitro de videiras cv. merlot e no crescimento micelial do fungo Elsinoe ampelina. Ci Agrotecnol. 2010;34:1425-30.

24. Xu H, Vavilin D, Vermaas W. Chlorophyll b can serve as the major pigment in functional photosystem II complexes of cyanobacteria. Proc Natl Acad Sci. 2001;98(24):14168-73, doi: 10.1073/pnas.251530298

25. Mahmoud SS, Croteau RB. Menthofuran regulates essential oil biosynthesis in peppermint by controlling a downstream monoterpene reductase. Proc Natl Acad Sci. 2003;100(24):14481-6, doi: $10.1073 /$ pnas. 2436325100 
26. Croteau R, Kutchan TM, Lewis NG. Natural products (secondary metabolites). Biochem mol biol plants. 2000;24:1250-319.

27. Gorelick J, Rosenberg R, Smotrich A, Hanuš L, Bernstein N. Hypoglycemic activity of withanolides and elicitated Withania somnifera. Phytochem. 2015;116:283-9, doi: 10.1016/j.phytochem.2015.02.029

28. Brasili E, Praticò G, Marini F, Valletta A, Capuani G, Sciubba F, et al. A non-targeted metabolomics approach to evaluate the effects of biomass growth and chitosan elicitation on primary and secondary metabolism of Hypericum perforatum in vitro roots. Metabolomics. 2014;10(6):1186-96, doi: $10.1007 / \mathrm{s} 11306-014-0660-\mathrm{z}$

29. Kamalipourazad M, Sharifi M, Maivan HZ, Behmanesh M, Chashmi NA. Induction of aromatic amino acids and phenylpropanoid compounds in Scrophularia striata Boiss. cell culture in response to chitosaninduced oxidative stress. Plant Physiol Biochem. 2016;107:374-84, doi: 10.1016/j.plaphy.2016.06.034 